\title{
Techniques for On-Line Diagnosis of Stator Shorted Turns in Induction Motors
}

\author{
I. ALBIZU \\ I. ZAMORA
}

A. J. MAZON

Electrical Engineering Department Faculty of Engineering of Bilbao The University of the Basque Country

\section{A. TAPIA}

Systems Engineering and Control Department Polytechnic University College of Donostia-San Sebastian The University of the Basque Country

\begin{abstract}
In low voltage induction motors, the first indication of a stator fault is the appearance of an inter-turn short circuit. For this reason, several attempts to diagnose reliably these short circuits have been made. Although considerable research has been carried out, the diagnosis of inter-turn short circuits is not a mature technique yet. This paper presents and analyzes the on-line inter-turn short circuit diagnostic techniques developed so far for line-connected induction motors. By means of a comparative study, their advantages and drawbacks are highlighted.
\end{abstract}

Keywords induction motors, on-line diagnosis, stator shorted turns

\section{Introduction}

The main cause of stator winding faults in induction motors is the degradation of the insulation [1]. The ageing process, the surface contamination and the vibration are causes of premature degradation. Another cause of degradation is the use of PWM converters.

The diagnostic strategy depends on the voltage level [2,3]. If the voltage level is above $4 \mathrm{kV}$, it is possible to apply the partial discharge monitoring approach. The identification of the deterioration of the insulation allows repairing it before failure. This technique is widely applied in industry [4-6]. But, if the voltage level is below $4 \mathrm{kV}$, this technique can not be applied. In this case, the first indication of a problem will be that a fault actually develops. For this reason, techniques for on-line inter-turn short circuit diagnosis are needed (Fig.1).

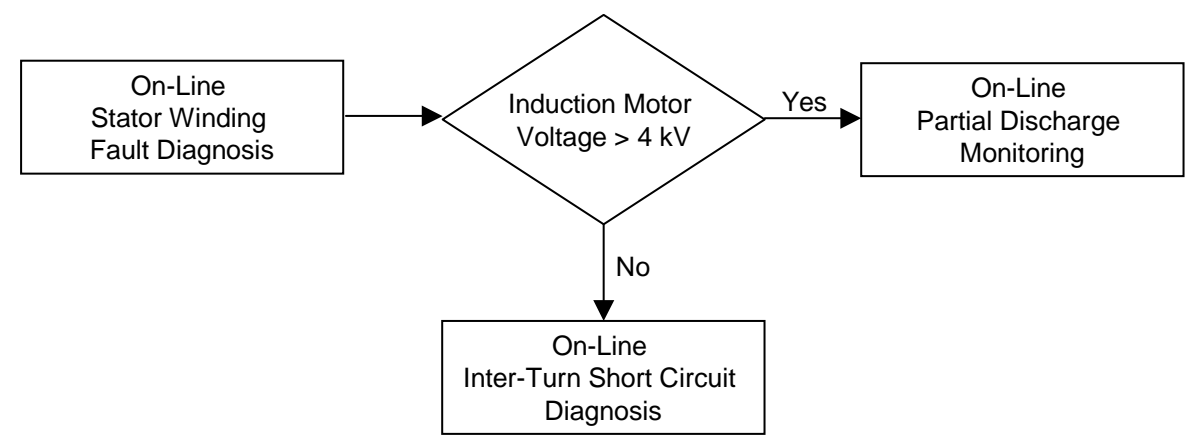

Figure 1. On-line stator winding fault diagnosis depending on the voltage of the induction motor 
The stator faults start with inter-turn short circuits within a coil. After this, serious faults such as phase-to-phase or phase-to-earth short circuits can be developed. An early diagnosis prevents the machine from these serious faults that can destroy the stator core. If the stator shorted turns are detected on time, only a small part of the winding is damaged and the motor can be repaired. As rewinding the motor is usually faster than replacing it, an early detection of shorted turns is very useful.

Hence, below $4 \mathrm{kV}$, the diagnostic strategy consists on the detection of inter-turn short circuits within a coil. Although considerable research has been carried out, the diagnosis of inter-turn short circuits is not a mature technique yet.

The diagnostic methods described in this paper are intended for line-connected induction motors. For inverter-fed motors, additional considerations have to be taken into account.

\section{On-Line Diagnosis of Stator Shorted Turns in Induction Motors}

The diagnostic techniques of stator shorted turns can be divided into those that are based on signature analysis and those that are based on stator asymmetry (Table I).

TABLE I. CLASSIFICATION OF ON-LINE DIAGNOSTIC TECHNIQUES OF STATOR SHORTED TURNS

\begin{tabular}{|l|l|}
\hline \multicolumn{2}{|c|}{ On-Line Diagnosis of Stator Shorted Turns } \\
\hline \multicolumn{1}{|c|}{ Stator Asymmetry } & \multicolumn{1}{c|}{ Signature Analysis } \\
\hline • Negative-Sequence Current & $\bullet$ Axial Leakage Flux \\
- Sequence Impedances & $\bullet$ Current \\
- Zero-Sequence Voltage & $\bullet$ Electromagnetic Torque \\
& $\bullet$ Vibration \\
\hline
\end{tabular}

The inter-turn short circuit increases the asymmetry of the stator winding. Hence, the negativesequence components change when a fault occurs. For this reason, some techniques are based on the detection of changes in the negative-sequence current [7-21]. These techniques are based on the monitoring of current and voltage of the three phases of the motor. Sequence components of the impedance are also considered for diagnostic purposes [22-32]. A technique based on zero-sequence voltage is also proposed [33].

An inter-turn short circuit also produces some changes in the harmonic components of rotor and stator currents and axial leakage flux. For this reason, some on-line diagnostic techniques are based on signature analysis of axial leakage flux [34-39] or line current [40-50]. Other magnitudes such as electromagnetic torque [51] and vibration [52-53] also show changes in the frequency spectrum.

Some of the mentioned diagnostic techniques require the installation of additional sensors that may be invasive to the motor's environment. This is the case of the axial leakage flux signature analysis 
and the vibration signature analysis. Other diagnostic techniques do not require the installation of additional sensors as they are based on the monitoring of voltage and current. The non-invasive stator fault diagnosis is the preferred option for condition monitoring of induction motors.

In order to validate the proposed diagnostic techniques, the researchers have carried out experimental tests with faulted motors. Most test motors are built with several taps in the winding in order to simulate inter-turn short circuits safely. These taps are connected through a variable resistor in order to limit the short circuit current. Only a few experiments have allowed the inter-turn short circuit to develop into a more severe fault $[16,27,48]$. In [48] a piece of copper was soldered onto the end winding of a coil and when, after a few minutes, ignition of the end winding tape occurred, the test was stopped. In [27], the insulation in two adjacent turns of one coil was scratched and these two turns were welded. The test was carried out until, after a few minutes, the final breakdown occurred and the phase-to-earth protection was set off. Finally, in [16], the insulation degradation is accelerated by thermally-induced stress. The moment the inter-turn short circuit occurs is unknown. This test is the closest to a real fault.

\section{On-Line Diagnosis based on Stator Asymmetry}

\subsection{Negative-Sequence Current}

An inter-turn fault in the stator winding leads to an asymmetry between the three phases, changing the negative-sequence component in the line current. The first study of the effect of inter-turn short circuits in the negative-sequence current was presented in [7]. Both analytical and experimental results showed an increase in negative-sequence current with the inter-turn short circuits.

The monitoring of the current negative-sequence component $I_{a 2}$ is easy as it is calculated from the measurements of the three line currents (1).

$$
I_{a 2}=\frac{1}{3}\left(I_{a}+a^{2} I_{b}+a I_{c}\right) \quad \text { where } a=e^{j 2 \pi / 3}
$$

However, inherent motor asymmetries, mismatched instrumentation gains and unbalanced supply voltages produce a similar effect (Fig. 2). These non-idealities have to be taken into account in the fault detection strategy. In fact, results show that there is negative-sequence current in healthy motors due to these factors. This asymmetry increases when an inter-turn fault occurs. When the motor is not symmetric, the positive and negative sequences become interdependent. In this case, there will be negative-sequence current even if the supply voltage is symmetrical and has no negative-sequence component. 


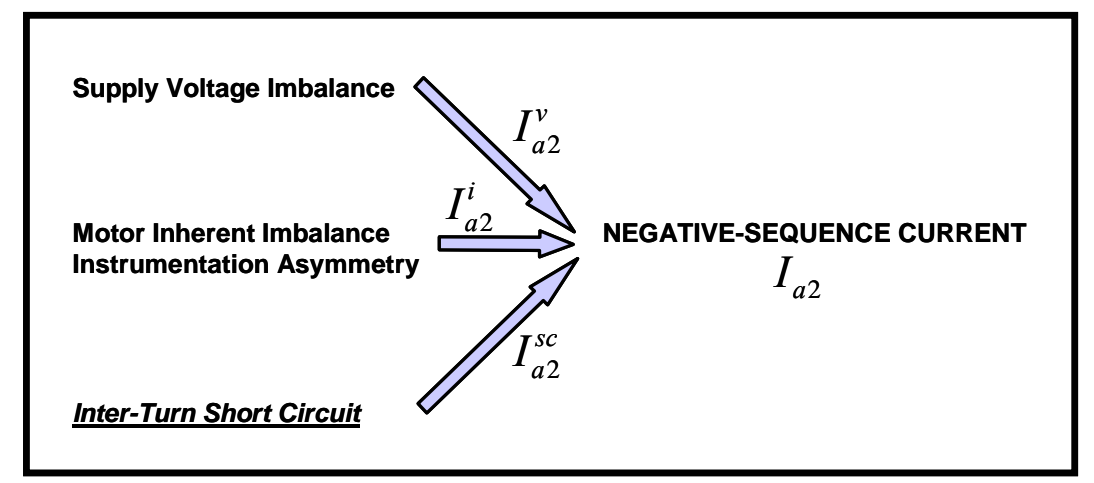

Figure 2. Different causes of negative-sequence current

Therefore, the measured negative-sequence current $I_{a 2}$ is the contribution of three components (2). Subtracting the current due to voltage imbalance $I_{a 2}^{v}$ and the inherent current $I_{a 2}^{i}$ from the measured negative-sequence current $I_{a 2}$, the current due to the fault $I_{a 2}^{s c}$ is obtained (3). An increase of its value will be indicative of inter-turn short circuit.

$$
\begin{aligned}
& I_{a 2}=I_{a 2}^{v}+I_{a 2}^{i}+I_{a 2}^{s c} \\
& I_{a 2}^{s c}=I_{a 2}-I_{a 2}^{v}-I_{a 2}^{i}
\end{aligned}
$$

\subsubsection{Database for Compensation of Inherent Asymmetries}

In [8,9], the negative-sequence current due to supply voltage imbalance $I_{a 2}^{v}$ is calculated as the relation between the negative-sequence voltage $V_{a 2}$ and the negative-sequence impedance of the motor $Z_{a 2}$ (4).

$$
I_{a 2}^{v}=\frac{V_{a 2}}{Z_{a 2}}
$$

The actual negative-sequence impedance $Z_{a 2}$ is considered a constant value independent of load. It is also supposed that its value does not change with the inter-turn short circuit.

The negative-sequence current due to the fault $I_{a 2}^{s c}$, is modeled as a current source in the negativesequence circuit. The negative-sequence current due to inherent asymmetries $I_{a 2}^{i}$ is also considered as a current source. Hence, the measured negative-sequence current is given by (5).

$$
I_{a 2}=\frac{V_{a 2}}{Z_{a 2}}+I_{a 2}^{i}+I_{a 2}^{s c}
$$

The negative-sequence current due to inherent asymmetries $I_{a 2}^{i}$ is supposed to be function of the load, the voltage and the frequency. However, the frequency is not expected to have a large effect in lineconnected motors. Hence, frequency influence is not considered. The $I_{a 2}^{i}$ value is calculated and 
stored in a database as a function of the voltage and load, represented by the positive-sequence values of voltage $V_{a l}$ and current $I_{a l}$ respectively.

The main inconvenience is the need for a database of $I_{a 2}^{i}$. The authors propose a self-tuning system that requires no special training period. Assuming that the motor has no turn faults, the current $I_{a 2}^{i}$ is calculated and stored while $V_{a l}$ and $I_{a l}$ vary over the normal ranges of the motor operating conditions.

In order to detect the fault reliably, an adaptive threshold for $I_{a 2}^{s c}$ is proposed. This threshold will be a multiple of the uncertainty of the calculation of $I_{a 2}^{s c}$. A value between two and three is adopted.

\subsubsection{Formulas for Compensation of Non-Idealities}

The assumption that $Z_{a 2}$ is constant [8,9] is not valid for many motors [10-12]. In fact, both the resistive $R_{a 2}$ and the reactive $X_{a 2}$ components of $Z_{a 2}$ are variable.

$$
Z_{a 2}=R_{a 2}+j X_{a 2}
$$

Temperature changes in the motor will be reflected in a change of the resistance $R_{a 2}$. For this reason, instead of calculating $I_{a 2}^{v}$ as a function of $Z_{a 2}$ (4), it is proposed to calculate it as a function of $X_{a 2}$ and the phase angle $\theta_{\mathrm{n}}$ between $V_{a 2}$ and $I_{a 2}(7)$.

$$
I_{a 2}^{v}=\frac{V_{a 2} \sin \theta_{n}}{X_{a 2}}
$$

This technique is valid if the phases of $I_{a 2}^{v}$ and the measured $I_{a 2}$ are the same. However, the variable negative-sequence current due to inherent asymmetries $I_{a 2}^{i}$ and inter-turn short circuits $I_{a 2}^{s c}$ could change the value of $\theta_{\mathrm{n}}$. The authors do not analyze these assumptions.

Anyway, $X_{a 2}$ is not a constant value as it depends on the degree of supply imbalance and load. In motors with closed rotor slots, with load changes and supply voltage imbalance, $X_{a 2}$ can vary between $10 \%$ and $50 \%$ as a consequence of leakage inductance saturation [13]. The orientation of the voltage imbalance $\phi_{\mathrm{n}}$ also influences the value of $X_{a 2}$ due to the static eccentricity of the rotor. In order to account for all these effects a semi-empirical formula is proposed (8).

$$
X_{a 2}^{-1}=\gamma_{0}+\gamma_{1} V_{a 2}+\gamma_{2} \sin 2 \phi_{n}+\gamma_{3} \cos 2 \phi_{n}+\gamma_{4} I_{a 1 x}+\gamma_{5} I_{a 1 y}^{2}
$$

The $V_{a 2}$ and $\phi_{\mathrm{n}}$ variables allow to relate $X_{a 2}$ with the supply imbalance and orientation respectively. The current $I_{a l x}$ is the component of $I_{a l}$ that is in phase with the supply voltage and represents the load, allowing to relate $X_{a 2}$ with load variation. Finally, $I_{a l y}$ is in quadrature with the supply voltage and represents the magnetization current, allowing to relate $X_{a 2}$ with flux saturation. 
Hence, equation (7) can be written as:

$$
I_{a 2}^{v}=V_{a 2} \sin \left(\theta_{n}\right)\left(\gamma_{0}+\gamma_{1} V_{a 2}+\gamma_{2} \sin 2 \phi_{n}+\gamma_{3} \cos 2 \phi_{n}+\gamma_{4} I_{a 1 x}+\gamma_{5} I_{a 1 y}^{2}\right)
$$

With respect to the negative-sequence current due to inherent asymmetries $I_{a 2}^{i}$, in order to describe its dependence with load and voltage a formula with quadratic functions of $I_{a l x}$ and $I_{a l y}$ is proposed (10). The current $I_{a l x}$ represents the load and $I_{a l y}$ represents the voltage.

$$
I_{a 2}^{i}=\alpha_{0}+\alpha_{1} I_{a 1 x}+\alpha_{2} I_{a 1 x}^{2}+\alpha_{3} I_{a 1 y}+\alpha_{4} I_{a 1 y}^{2}
$$

In order to characterize the $\gamma_{\mathrm{i}}$ and $\alpha_{\mathrm{i}}$ parameters, it is proposed to carry out the characterization of the voltage imbalance calculating the $\gamma_{\mathrm{i}}$ parameters. Then, the voltage and load variation are considered and the $\alpha_{i}$ parameters are calculated. The recursive least squares method is proposed to calculate these parameters.

Finally, instead of calculating the negative-sequence current with (1), a power decomposition technique (PDT) is proposed to calculate the positive and negative sequences of current and voltage in real time.

\subsubsection{Neural Network for the Calculation of $I^{s c} \underline{a 2}$}

In [14-16] a diagnostic approach based on an artificial neural network (ANN) is proposed. The inputs of the ANN are the voltage negative-sequence $V_{a 2}$, the voltage positive-sequence $V_{a 1}$ and the current positive-sequence $I_{a l}$. The output of the ANN is the negative-sequence current $I_{a 2}^{*}$ due to voltage imbalance and inherent asymmetries (11).

$$
I_{a 2}^{*}=I_{a 2}^{v}+I_{a 2}^{i}
$$

In the monitoring stage, this estimated value $I_{a 2}^{*}$ is compared with the measured value $I_{a 2}$. A deviation of $I_{a 2}$ with respect to $I_{a 2}^{*}$ will be an indication of fault (12).

$$
I_{a 2}^{s c}=I_{a 2}-I_{a 2}^{*}
$$

At the beginning, an off-line training of the ANN was proposed [14]. The ANN is trained over the entire range of operation conditions expected. This scheme, known as global minimum training (GMT) is not suitable for practical implementation, as it requires considerable data memory and computation.

For this reason other training algorithms, more suitable for on-line application were proposed $[15,16]$. These algorithms are the continual on-line training (COT), the quasi-global minimum 
training (QGMT) and the combination of both (COT-QGMT). These algorithms have lower computation and data storage requirements than the GMT.

In the COT algorithm, the ANN weights are continuously updated. Instead of considering all the operation conditions, only a neighborhood of the current operating condition is considered. In order to update the ANN continuously, every time interval is divided into one training slot and several monitoring slots. The limitation of the COT is that if the fault develops slowly, this is not detected. However, when the fault occurs rapidly the COT is a good detector.

In the QGMT algorithm, the healthy motor operating conditions are stored in a dynamic database of limited size. This database is created and modified on-line and instead of containing the entire range of operation conditions as in the GMT, only the most recently operation conditions are stored. If a large shift in the operation conditions occurs, the ANN exhibits a large estimation error and a false alarm may appear.

The COT and QGMT algorithms are complementary. For this reason, a combination of both schemes is proposed. Two ANN are used. One is trained by the COT scheme whereas the other is trained by the QGMT scheme. Although both ANN are continuously updated only one of them is used for monitoring the fault. The QGMT scheme is used for monitoring the fault and when a large shift in the operation conditions occurs, the protection is switched to the COT algorithm.

\subsubsection{Current Space Vector}

Some authors have proposed the monitoring of current space vector in order to detect the increase in the negative-sequence current [17-19]. Both the amplitude and phase of the current space vector are influenced by the negative-sequence current.

In a symmetrical motor with balanced supply, the current space vector amplitude is constant. If there is motor asymmetry, supply imbalance or inter-turn fault, the amplitude will have an ac component at twice the fundamental supply frequency $(2 f)$. This component is proposed for the motor condition monitoring in $[17,18]$.

The negative-sequence current also has influence in the angular position of the current space vector. In an ideal situation the angular position increments its value uniformly at angular frequency $\omega$. In the presence of negative-sequence component, the angular position fluctuates at twice the fundamental supply frequency (2f). Hence, angular fluctuation can be used as fault indicator [19]. The angular fluctuation $\delta \theta$ is calculated subtracting the expected increment in angular position $\omega t$ from the actual position $\theta$ :

$$
\delta \theta=\theta-\omega t
$$




\subsubsection{Neural Network for Estimation of Fault Severity}

In $[20,21]$, an artificial neural network is used to evaluate the severity of the inter-turn short circuit. The output of the ANN is the short-circuited turn percentage. The input values are the slip and the current positive and negative sequences.

In order to train the supervised ANN, a mathematical model is used. The supply voltage is supposed to be balanced. As the model does not take into account non-idealities, the ANN would have difficulties in the condition monitoring of real motors.

\subsection{Sequence Impedances}

Due to the difficulties associated to the negative-sequence current, a research group proposed the effective negative-sequence impedance as fault indicator [22-24]. In order to overcome the limitations of this fault indicator the same research group proposed the sequence impedance matrix [28-31].

\subsubsection{Effective Negative-Sequence Impedance}

Due to the difficulties associated to the negative-sequence current, a different fault indicator was proposed [22-24]. It is known as effective negative-sequence impedance (14).

$$
Z_{a 2 e f f}=\frac{V_{a 2}}{I_{a 2}}
$$

The calculation of this indicator is simple and it requires no initial training. However, it is not possible to evaluate the fault severity. In addition, the motor and sensors asymmetries decrease considerably the sensitivity of the indicator. This is because equation (14) is true only if the motor is perfectly symmetric. If this is not the case, there is an interaction between the sequence components.

Another research team has studied this method [25-27] and similar results have been obtained. In addition, they have developed an improved method for the calculation of the effective negativesequence impedance [26].

\subsubsection{Sequence Impedance Matrix}

It may be shown that the relation between voltage and current sequence components is as indicated in equation (15).

$$
\left[\begin{array}{c}
V_{a 0} \\
V_{a 1} \\
V_{a 2}
\end{array}\right]=\left[\begin{array}{lll}
Z_{00} & Z_{01} & Z_{02} \\
Z_{10} & Z_{11} & Z_{12} \\
Z_{20} & Z_{21} & Z_{22}
\end{array}\right]\left[\begin{array}{c}
I_{a 0} \\
I_{a 1} \\
I_{a 2}
\end{array}\right]
$$


For a symmetrical motor, the off-diagonal terms of the sequence component impedance matrix are zero and the sequence components are independent to each other. However, due to the inherent asymmetries of the motors, the off-diagonal terms are nonzero and the sequence components are not decoupled.

Assuming that the zero-sequence component of the line current is equal to zero $\left(I_{a 0}=0\right)$ :

$$
\left[\begin{array}{c}
V_{a 1} \\
V_{a 2}
\end{array}\right]=\left[\begin{array}{ll}
Z_{11} & Z_{12} \\
Z_{21} & Z_{22}
\end{array}\right]\left[\begin{array}{l}
I_{a 1} \\
I_{a 2}
\end{array}\right]
$$

The $Z_{x y}$ parameters depend on the motor design and construction, the operating speed and the presence of a winding fault. Hence, the change that is produced by the fault can be used as indicative of fault. However, for a reliable diagnosis, the effects of speed and inherent imbalances have to be considered (Fig. 3).

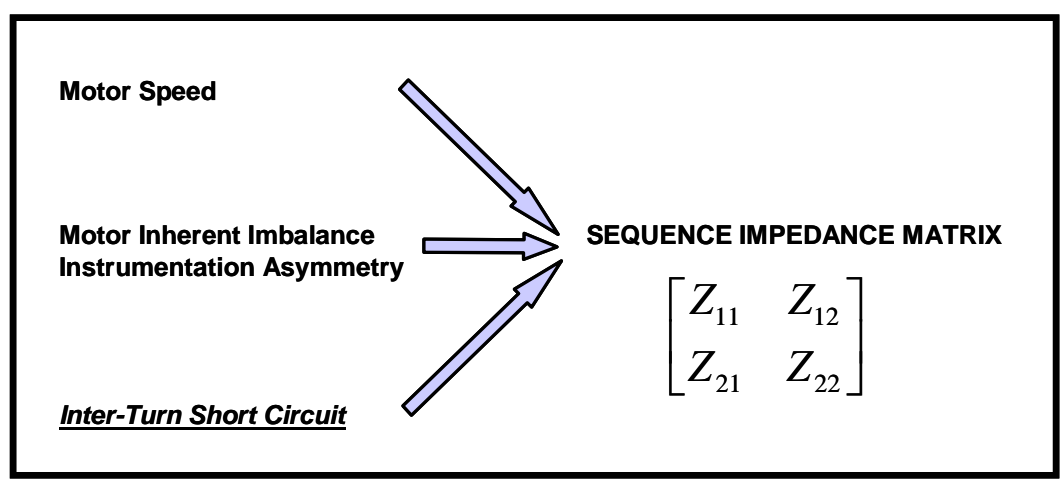

Figure 3. Magnitudes that affect the sequence impedance matrix

\subsubsection{Voltage Mismatch}

In [28-31], the change in the sequence impedance matrix is used for the diagnosis. The method is known as voltage mismatch detector and it is based on the deviation of the voltage sequence components due to the fault.

In the learning stage, the values of $Z_{11}, Z_{12}, Z_{21}$ and $Z_{22}$ are calculated from two independent tests for several motor speed values. These values are stored in a database.

In the protection stage, monitoring the voltage and line current, $V_{a l}, V_{a 2}, I_{a 1}$ and $I_{a 2}$ are obtained. Knowing the speed, from $I_{a 1}, I_{a 2}$ and equation (16) the expected values of $V_{a 1}$ and $V_{a 2}$ are obtained and compared with the measured ones. If an inter-turn short circuit occurs the $Z_{x y}$ parameters change and a voltage mismatch is observed. This deviation is used as fault indicator.

This fault indicator is independent of the motor and sensors inherent asymmetries because these effects are considered when the $Z_{x y}$ parameters are calculated. For this reason, the same sensors have 
to be used during the condition monitoring. The method is also independent of imbalances in the power supply.

\subsubsection{Off-Diagonal Sequence Impedance}

A similar approach is proposed in [32]. In this case, the fault indicator is the off-diagonal sequence component $Z_{12}$.

In the learning stage, $Z_{12}$ is calculated and stored for several speed values. From (16), the value of $Z_{12}$ can be calculated from two linearly independent tests carried out at a certain speed (17). The supply imbalance has to be different from one test to another. The sequence components of the first test are $I_{a 1}^{I}, I_{a 2}^{l}$ and $V_{a 2}^{l}$ and the values of the second test are $I_{a 1}^{2}, I_{a 2}^{2}$ and $V_{a 2}^{2}$.

$$
Z_{12}=\frac{I_{a 2}^{2} V_{a 2}^{1}-I_{a 2}^{1} V_{a 2}^{2}}{I_{a 1}^{1} I_{a 2}^{2}-I_{a 1}^{2} I_{a 2}^{1}}
$$

The supply is intentionally unbalanced in order to obtain independent tests. The first test is carried out without any intentional imbalance and for the second test the supply is unbalanced. The value of $Z_{12}$ and the sequence components of the balanced test are stored as a function of speed. If there is not speed measurement available, the positive-sequence impedance value $Z_{a l}$ is proposed to represent it. This magnitude is supposed to be a function only of speed. Hence, this value is stored as well.

In the protection stage, $Z_{12}$ is continuously calculated from the current and voltage measurements and the stored data. In order to calculate $Z_{12}$, besides the continuously measured sequence component values, the stored sequence components of the balanced test are used. In order to evaluate the speed, $Z_{a 1}$ is continuously calculated. A deviation of $Z_{12}$ will be indicative of fault.

\subsection{Zero-Sequence Voltage}

A different approach for star connected motors with the neutral accessible is proposed in [33]. The fault indicator is the sum of the three instantaneous line-neutral voltages. In an ideal case its value is zero. If an inter-turn short circuit occurs its value increases.

One of the drawbacks of the approach is the need of the neutral to be accessible. Furthermore, in an actual healthy machine the fault indicator is not zero due to machine inherent imbalance and instrumentation asymmetry. Although the effects of load and voltage imbalance are neglected in the approach, this consideration is based on a symmetrical machine impedance. Hence, in an actual machine with inherent asymmetries, these effects could decrease the sensitivity of the method. 


\section{On-Line Diagnosis based on Signature Analysis}

\subsection{Axial Leakage Flux Signature Analysis}

It has been shown that axial flux monitoring can detect inter-turn short circuits [34-39]. The perfect electric motor does not produce any axial flux because the currents flowing in the end windings of the rotor and stator circuits are perfectly balanced. However, there are always small asymmetries in both the material and geometric aspects of the magnetic and electric circuits of any motor. This results in every motor producing a small, but measurable axial leakage flux. If a coil is wound around the shaft of the motor, it will have induced in it a voltage that can be related to the axial flux.

Both stator and rotor windings produce axial leakage flux that is a result of the winding currents. Hence, the axial leakage flux spectral content may be related directly to the harmonic components present in the winding currents. These components depend on the harmonic components of the air gap flux.

A stator inter-turn short circuit changes the distribution of the magnetomotive force (MMF) in the air gap because of the current that circulates through the short-circuited turns. The MMF distribution due to the inter-turn short circuit induces different frequencies in the rotor currents and so in the axial leakage flux [34,35]. These frequency values are given by (18), where $f$ is the fundamental frequency of the supply, $k$ is the supply voltage harmonic order, $p$ is the number of pole pairs, $s$ is the fractional slip and $n$ is an integer different from $2 p m$ for $m=1,2,3 \ldots$

$$
(k \pm n(1-s) / p) f
$$

Experimental results [27,35-39] show that these frequency components are present in healthy motors of different characteristics and sizes. This occurs because of the stator inherent asymmetry. Therefore, the short circuit does not give new components but changes their values. Results show an increase in these values when an inter-turn short circuit occurs.

These frequencies vary slightly depending on the motor loading or slip $s$ (18). As the motor loading changes, their magnitude also changes. Results have shown that these components are very load dependent. In fact, the differences can be higher between no load and full load than between healthy stator and stator with short-circuited turns. Only when the short-circuited turn percentage is high, $16 \%$ as shown in [36], it is possible to discern between a short circuit and a load change.

Hence, the main drawback of axial leakage flux signature analysis is its high dependency on load. This can be a problem for reliable diagnosis. Furthermore, the search coil is invasive to the motor's environment. 


\subsection{Current Signature Analysis}

Monitoring of line current is the preferred option for condition monitoring of induction motors. The main reason is that current monitoring is non-invasive. In fact, most rotor fault and eccentricity diagnostic techniques are based on stator current signature analysis. For this reason, several studies have been carried out in order to study current signature changes with inter-turn short circuits.

These studies certify that some frequency components change their amplitudes with inter-turn faults. However, the theoretical frequency values that are function of fault, change from study to study. Furthermore, among the frequencies predicted to change, some show a higher sensitivity to the fault than others. The most sensitive values are verified after experimental tests. This means a difficulty for the diagnosis.

\subsubsection{Rotor Slot Harmonics}

Some studies show that rotor slot harmonics reflected in the time harmonics of the stator current (19) increase their value with inter-turn short circuits [40-46]:

$$
\left(k^{\prime}\left(N_{r} / p\right)(1-s) \pm 1\right) f
$$

$N_{\mathrm{r}}$ is the number of rotor slots and $k^{\prime}$ is an integer value.

A symmetrical healthy stator winding picks up only those harmonics present in the rotor MMF whose pole pair numbers match with those the stator winding itself can produce. However, with an inter-turn short circuit, the shorted portion of the winding acts as a pick-up coil for all these harmonics, irrespective of their pole pair numbers. These harmonics will be induced in the healthy portion of the winding.

As there are always small inherent asymmetries, these values are also present in healthy motors signature. For this reason, the fault does not give new components but changes their values. Simulations [40-44,46] and experimental tests $[40,44,45]$ verify this statement.

However, the increase in their values can be small [44]. Furthermore, simulations carried out in [41-43] show that rotor slot harmonics weakly depend on the mechanical load. These simulations also show that these harmonics are independent of supply imbalance.

Other simulation results show that there is a dependence on supply imbalance [46]. For this reason, the detection of the rotor slot harmonics when the motor is switched-off is proposed. The method is based on the monitoring of the line-to-line voltage. Experimental results verify the validity of the approach. 


\subsubsection{Third Harmonic}

Simulation and experimental results carried out in $[40,44]$ also show an increase of the current $3^{\text {rd }}$ harmonic with the inter-turn fault. However, this component already exists due to magnetic saturation. Furthermore, it is also sensitive to supply imbalance and machine inherent asymmetries.

\subsubsection{Stavrou et al}

In [47], based on the interaction of the MMF and the permeance waves in the air gap, the harmonics that are expected to vary due to inter-turn faults are obtained. These harmonics can have their origin either in the stator currents $f_{s c}$ (20) or in the rotor currents $f_{r c}$ (21).

$$
\begin{gathered}
f_{s c}=\left(j_{r t} N_{r} \frac{1-s}{p} \pm 2 j_{s a} \pm i_{s t}\right) f \\
f_{r c}=\left(\left(j_{r t} N_{r} \pm k^{\prime}\right) \frac{1-s}{p} \pm 2 j_{s a} \pm i_{r t} s\right) f
\end{gathered}
$$

The parameters $j_{r t}, j_{s a}, i_{s t}, k^{\prime}, i_{r t}$ are integer values. The subscripts $r t, s t$, and $s a$ are related to slotted rotor, slotted stator and saturation respectively.

Experimental results show that the change in the magnitude of the frequencies given by (20) and (21) is not the same in all of them. Some frequencies even decrease their values. And the results vary if different motors are considered. The most sensitive frequencies are the lower sidebands given by (21) and one of the components given by (20). For the calculation of the frequencies using equation (21) slotting and saturation have been neglected $\left(j_{r t}=0, j_{s a}=0\right)$.

\subsubsection{Thomson et al}

Finally, there has to be mentioned the research study presented in [48,49]. Although there is a lack of theoretical justification, the experimental results are promising. The components that are function of shorted turns are given by (22).

$$
\left(k^{\prime}(1-s) / p \pm k\right) f
$$

Experimental results show that the increase in the components given by $\left(k=1, k^{\prime}=3\right)$ and $\left(k=1, k^{\prime}=5\right)$ can be identified. Similar results are obtained in the three phases. Therefore, it is enough if the condition monitoring is carried out monitoring only one phase current. Furthermore, the effect of load is negligible compared to the change that occurs between healthy and faulty motor.

Based on these results, there is in development a hand-held device based on current signature analysis for the detection of several faults, including shorted stator turns [50]. 


\subsection{Electromagnetic Torque Signature Analysis}

Signature analysis of electromagnetic torque for diagnostic purposes has also been analyzed [27,51]. The frequencies that are present in the spectrum of a healthy motor are the following:

- Double supply frequencies:

- Multiples of the rotating speed:

$$
k^{\prime}(1-s) f / p
$$

- Combinations of them:

$$
2 f+k^{\prime}(1-s) f / p
$$

Experimental results show that with inter-turn short circuits, sidebands of the multiples of the rotating speed appear at $\pm 2 f s$. In addition, frequencies present before the fault increase their value.

\subsection{Vibration Signature Analysis}

Signature analysis of electrically-excited radial vibration is presented in [52-53]. Due to the link between electrical behavior and mechanical vibration of induction motors, internal fault currents can be detected by vibration measurement.

In [52], the induction motor is considered as a system and the signal given by a piezoelectric accelerometer installed on the motor casing is considered as the output of the system. By means of a higher order spectra signal-processing tool, different faults are identified: broken rotor bars, dynamic eccentricity and inter-turn short circuits.

In [53], some vibration frequencies related to stator shorted turns are determined theoretically and they are verified experimentally. Besides installing an accelerometer on the stator casing, accelerometers are installed on both rotor bearings. The latter show to be more sensitive.

Although results show that the faults are detected, the approach seems less sensitive than those that are based on electrical magnitudes. Furthermore, the installation of an accelerometer can be invasive to the motor's environment. In any case, vibration signature analysis can be useful as a supplement other techniques.

\section{Comparative Analysis}

Several diagnostic techniques have been presented. These techniques differ in the fault indicator that is used for diagnosis. Whatever the fault indicator is, the important issue is that the diagnosis is carried out efficiently. The simplicity for practical implementation is also desirable. Therefore, the presented diagnostic methods are compared in terms of diagnostic efficiency and requirements for practical implementation. 
In order to address the issue of the diagnostic efficiency, basically the experimental results will be considered. Although simulations give an indication of the diagnostic efficiency, they do not consider non-idealities that affect the actual diagnosis. Non-idealities such as motor inherent asymmetries, supply voltage imbalances or instrumentation asymmetries difficult the actual diagnosis. Hence, so that diagnostic techniques give good results they should consider these non-idealities.

With respect to the simplicity for practical implementation, the first factor to consider is whether the technique is invasive or not. Non-invasive methods based on voltage or current monitoring are preferred. Another factor to consider is the need for data computation and memory.

Most of the diagnostic methods based on the asymmetry created by the turn fault are related with the changes in negative-sequence components when inter-turn faults occur [7-21]. The main inconvenience for diagnosis is that these negative-sequence components appear due to other factors apart from the fault. Inherent motor asymmetries, unbalanced supply voltages and mismatched instrumentation gains produce similar effects. Only if these effects are taken into account it will be possible to carry out a reliable diagnosis. For this reason, some diagnostic techniques include interesting compensation methods to overcome the effects of non-idealities [8-16]. These methods have a considerable need for data computation and memory. However, stress on their suitability for practical implementation has been put and this need has been reduced.

The first method based on sequence impedances did not considered the non-idealities [22-27]. However, in order to overcome the limitations of this fault indicator, the non-idealities were considered and the efficiency of the method improved considerably [28-32]. These techniques have also a considerable need for data computation and memory.

Among the techniques based on stator asymmetry, that based on zero-sequence voltage is the poorest [33]. The compensation of the non-idealities is not considered. In addition, there is the need of the neutral to be accessible. Finally, it has to be mentioned that there is only one paper published about this technique.

Diagnostic approaches based on the signature analysis of axial leakage flux, line current, electromagnetic torque and vibration have been presented. The researches carried out have shown that there are components of the spectra that are function of inter-turn faults. However, the experimental results have shown that there are some difficulties using these components for reliable diagnosis. In addition, some techniques require the installation of sensors that may be invasive to the motor's environment such as accelerometers or search coils. Furthermore, the calculation of the signature in real time requires considerable computation. 
The monitoring of axial leakage flux requires a search coil [34-39]. This is invasive to the motor's environment. However, the main drawback of axial leakage flux signature analysis is its high dependency on load.

The analysis of current signature has the advantage that is non-invasive [40-50]. However, the theoretical frequency values that are function of fault, change from study to study. In addition, the experimental results are not good. Among the frequencies predicted to change, some show a higher sensitivity to the fault than others. Furthermore, it is needed a great number of shorted turns so that the change in signature is detected.

The method based on electromagnetic torque signature is also non-invasive [51]. Similarly to current signature, among the frequencies predicted to change, some show a higher sensitivity to the fault than others. Finally, it has to be mentioned that there is only a research group that has experimented with this technique.

Finally, the vibration signature has been proposed for fault detection [52-53]. The accelerometer is invasive to the motor's environment. In addition, this technique is based on a complex signal processing that requires high computation [52]. Further research in this field is needed.

Table II summarizes the most relevant comparative aspects of the analyzed techniques in terms of diagnostic efficiency and requirements for practical implementation.

TABLE II. Summary OF THE COMPARATIVE ANALYSIS OF DiAgNOSTIC TECHNIQUeS

\begin{tabular}{|c|c|c|}
\hline & Diagnostic Efficiency & Simplicity for Practical Implementation \\
\hline $\begin{array}{c}\text { Negative-Sequence } \\
\text { Current }\end{array}$ & $\begin{array}{l}\text { High } \\
\text { v Compensation of non-idealities } \\
v \text { Good experimental results }\end{array}$ & $\begin{array}{c}\text { Medium } \\
\text { v Current and voltage monitoring } \\
x \text { High computation and memory requirement }\end{array}$ \\
\hline $\begin{array}{c}\text { Sequence } \\
\text { Impedances }\end{array}$ & $\begin{array}{l}\text { High } \\
\text { v Compensation of non-idealities } \\
\text { V Good experimental results }\end{array}$ & $\begin{array}{c}\text { Medium } \\
\text { v Current and voltage monitoring } \\
x \text { High computation and memory requirement }\end{array}$ \\
\hline $\begin{array}{l}\text { Zero-Sequence } \\
\text { Voltage }\end{array}$ & $\begin{array}{c}\text { Low } \\
x \text { Non-idealities are not compensated } \\
x \text { Lack of experimental results }\end{array}$ & $\begin{array}{c}\text { Medium } \\
v \text { Voltage monitoring } \\
x \text { Neutral has to be accessible }\end{array}$ \\
\hline $\begin{array}{l}\text { Axial Leakage } \\
\text { Flux Signature }\end{array}$ & $\begin{array}{c}\text { Low } \\
x \text { Load dependency }\end{array}$ & $\begin{array}{c}\text { Low } \\
x \text { Invasive (search coils) } \\
x \text { High computation requirement }\end{array}$ \\
\hline Current Signature & $\begin{array}{c}\text { Low } \\
x \text { Bad experimental results }\end{array}$ & $\begin{array}{c}\text { Medium } \\
\text { v Current monitoring } \\
x \text { High computation requirement }\end{array}$ \\
\hline $\begin{array}{l}\text { Electromagnetic } \\
\text { Torque Signature }\end{array}$ & $\begin{array}{c}\text { Low } \\
x \text { Lack of experimental results }\end{array}$ & $\begin{array}{c}\text { Medium } \\
v \text { Current and voltage monitoring } \\
x \text { High computation requirement } \\
\end{array}$ \\
\hline $\begin{array}{l}\text { Vibration } \\
\text { Signature }\end{array}$ & $\begin{array}{c}\text { Low } \\
x \text { Lack of experimental results }\end{array}$ & $\begin{array}{c}\text { Low } \\
x \text { Invasive (accelerometer) } \\
x \text { High computation requirement }\end{array}$ \\
\hline
\end{tabular}




\section{Conclusions}

The on-line inter-turn short circuit diagnostic techniques for line-connected induction motors developed so far have been presented and analyzed in this paper. These techniques have been divided into those that are based on signature analysis and those that are based on stator asymmetry.

A comparative study of the diagnostic techniques has been carried out. Stress on their diagnostic efficiency and simplicity for practical implementation has been put. Among all the analyzed diagnostic techniques those that are based on the asymmetry introduced by the short circuit seem to be the most promising. Compared to those based on signature analysis, they show both a higher efficiency and a better suitability for practical implementation. The compensation of non-idealities is the key to a reliable diagnosis. Hence, among all the described diagnostic techniques, those that carry out this compensation [8-16,28-32] seem the most promising.

\section{Acknowledgments}

This work was supported by the Basque Government under the research project PRECORES (Ref. S-PE04UN22).

\section{References}

[1] A.H. Bonnett, G.C. Soukup, "Cause and analysis of stator and rotor failures in three-phase squirrel-cage induction motors”, IEEE Transactions on Industrial Applications, Vol. 28, pp. 921-37, 1992.

[2] W.T. Thomson, "A review of on-line condition monitoring techniques for three-phase squirrel-cage induction motors past present and future”, IEEE Symposium on Diagnostics for Electrical Machines, Power Electronics and Drives SDEMPED'99, pp. 3-18, Gijón-Spain, 1999.

[3] R. Tallam, S.B. Lee, G. Stone, G.B. Kliman, J. Yoo, T.G. Habetler, R.G. Harley, “A survey of methods for detection of stator related faults in induction machines", IEEE Symposium on Diagnostics for Electrical Machines, Power Electronics and Drives SDEMPED'03, pp. 35-46, Atlanta-USA, 2003.

[4] D.G. Edwards, "On-line diagnosis of defects in the stator winding structures of high voltage rotating machines", International Conference on Electrical Machines ICEM’92, Manchester-UK, 1992.

[5] G.C. Stone, H.G. Sedding, M.J. Costello, "Application of partial discharge testing to motor and generator stator winding maintenance”, IEEE Transactions on Industry Applications, Vol. 32, No. 2, pp. 459-464, 1996.

[6] IEEE 1434-2000 - IEEE Trial Use Guide to the Measurement of Partial Discharges in Rotary Machinery.

[7] S. Williamson, K. Mirzoian, “Analysis of cage induction motors with stator winding faults”, IEEE Transactions on Power Apparatus and Systems, Vol. 104, No. 7, July, pp. 1838-42, 1985.

[8] G.B. Kliman, W.J. Premerlani, R.A. Koegl, D. Hoeweler, "A new approach to on-line turn fault detection in ac motors”, IEEE Industry Applications Society Conference, Vol. 1, pp. 687-93, San Diego-USA, 1996.

[9] G.B. Kliman, W.J. Premerlani, R.A. Koegl, D. Hoeweler, "Sensitive, on-line turn-to-turn fault detection in AC motors”, Electric Machines and Power Systems, Vol. 28, No. 10, pp. 915-27, 2000.

[10] M. Arkan, P.J. Unsworth, "Stator fault diagnosis in induction motors using power descomposition”, IEEE Industry Applications Society Conference, pp. 1908-12, 1999.

[11] M. Arkan, "Stator fault diagnosis in induction motors", PhD Dissertation, University of Sussex, UK, 2000.

[12] M. Arkan, D.K. Perovic, P. Unsworth, “Online stator fault diagnosis in induction motors”, IEE Proceedings - Electric Power Applications, Vol. 148, No. 6, pp. 537-47, 2001.

[13] M. Arkan, D.K. Perovic, P.J. Unsworth, “Closed rotor slot effect on negative sequence impedance”, IEEE Industry Applications Society Conference, pp. 751-53, 2001.

[14] R.M. Tallam, T.G. Habetler, R.G. Harley, D.J. Gritter, B. Burton, "Neural network based stator winding turn-fault detection for induction motors”, IEEE Industry Applications Society Conference, Vol. 1, pp. 375-80, Roma-Italy, 2000. 
[15] R.M. Tallam, T.G. Habetler, R.G. Harley, "Self-commisioning training algorithms for neural networks with applications to electric machine fault diagnostics”, IEEE Transactions on Power Electronics, Vol. 17, No. 6, pp. 108995, 2002.

[16] R. Tallam, T.G. Habetler, R.G. Harley, "Experimental testing of neural-network-based turn-fault detection scheme for induction machines under accelerated insulation failure conditions", IEEE Symposium on Diagnostics for Electrical Machines, Power Electronics and Drives SDEMPED'03, pp. 58-62, Atlanta, 2003.

[17] A.J.M. Cardoso, S.M.A. Cruz, D.S.D. Fonseca, "Inter-turn stator winding fault diagnosis in three-phase induction motors by Park’s vector approach”, IEEE Transactions on Energy Conversion, Vol. 14, No. 3, pp. 595-98, 1999.

[18] S.M.A. Cruz, A.J.M. Cardoso, "Stator winding fault diagnosis in three-phase synchronous and asynchronous motors, by the extended Park's vector approach”, IEEE Transactions on Industry Applications, Vol. 37, No. 5, pp. 1227-33, 2001.

[19] D.K. Perovic, M. Arkan, P. Unsworth, "Induction motor fault detection by space vector angular fluctuation”, IEEE Industry Applications Society Conference, pp. 388-94, 2000.

[20] F. Filippetti, G. Franceschini, C. Tassoni, S. Meo, A. Ometto, "Neural network aided on-line diagnostics of induction machine stator faults”, International Universities Power Engineering Conference UPEC'95, pp. 148-51, 1995.

[21] F. Filippetti, G. Franceschini, A. Ometto, S. Meo, "A survey of neural network approach for induction machine on-line diagnosis”, International Universities Power Engineering Conference UPEC'96, pp. 17-20, 1996.

[22] J.L. Kohler, J. Sottile, F.C. Trutt, “Alternatives for assessing the electrical integrity of induction motors”, IEEE Transactions on Industry Applications, Vol. 28, No. 5, pp. 1109-17, 1992.

[23] J. Sottile, J.L. Kohler, "An on-line method to detect incipient failure of turn insulation in random-wound motors", IEEE Transactions on Energy Conversion, Vol. 8, No. 4, pp. 762-68, 1993.

[24] J.L. Kohler, J. Sottile, F.C. Trutt, "Condition monitoring of stator windings in induction motors: Part I - Experimental investigation of the effective negative-sequence impedance detector”, IEEE Transactions on Industry Applications, Vol. 38, No. 5, pp. 1447-53, 2002.

[25] M.G. Melero, M.F. Cabanas, G.A. Orcajo, J.M. Cano, G.A. Capolino, "An automated insulation failure detection system for working induction motors”, European Conf. Power Electronics and Applications EPE'99, LausanneSwitzerland, 1999.

[26] M.F. Cabanas, M.G. Melero, G.A. Orcajo, J.M. Cano, F. Briz del Blanco, G.A. Capolino, “A new methodology for applying the FFT to induction motor diagnosis”, IEEE Symposium on Diagnostics for Electrical Machines, Power Electronics and Drives SDEMPED'99, pp. 537-43, Gijón-Spain, 1999.

[27] M.G. Melero, M.F. Cabanas, C.H. Rojas, G.A. Orcajo, J.M. Cano, J. Solares, "Study of an induction motor working under stator winding inter-turn short circuit condition”, IEEE Symposium on Diagnostics for Electrical Machines, Power Electronics and Drives SDEMPED'03, pp. 52-57, Atlanta-USA, 2003.

[28] F.C. Trutt, J. Sottile, J.L. Kohler, “Detection of electrical winding deterioration in induction motors”, Electric Power Components and Systems, Vol. 29, No. 11, pp. 1025-33, 2001.

[29] F.C. Trutt, J. Sottile, J.L. Kohler, “Online condition monitoring of induction motors”, IEEE Transactions on Industry Applications, Vol. 38, No. 6, pp. 1627-32, 2002.

[30] J.L. Kohler, J. Sottile, F.C. Trutt, "Condition monitoring of stator windings in induction motors: Part II Experimental investigation of voltage mismatch detectors”, IEEE Transactions on Industry Applications, Vol. 38, No. 5, pp. 1454-59, 2002.

[31] J. Sottile, F.C. Trutt, J.L. Kohler, “Application of online voltage mismatch condition monitoring of induction motor stator windings in a mining environment”, IEEE Industry Applications Society Conference, pp. 1637-44, 2003.

[32] S.B. Lee, R.M. Tallam, T.G. Habetler, “A robust, on-line turn-fault detection technique for induction machines based on monitoring the sequence component impedance matrix", IEEE Transactions on Power Electronics, Vol. 18, No. 3, pp. 865-72, 2003.

[33] M.A. Cash, T.G. Habetler, G.B. Kliman, "Insulation failure prediction in AC machines using line-neutral voltages", IEEE Transactions on Industry Applications, Vol. 34, No. 6, pp. 1234-39, 1998.

[34] J. Penman, M.N. Dey, A.J. Tait, W.E. Bryan, “Condition monitoring of electrical drives”, Proceedings IEE - Part B Electric Power Applications, Vol. 133, No. 3, pp. 142-48, 1986.

[35] J. Penman, H.G. Sedding, B.A. Lloyd, W.T. Fink, "Detection and location of interturn short circuits in the stator windings of operating motors”, IEEE Transactions on Energy Conversion, Vol. 9, No. 4, pp.652-58, 1994.

[36] M.F. Cabanas, M.G. Melero, G.A. Orcajo, F.R. Faya, J. Solares, "Experimental application of axial leakage flux to the detection of rotor asymmetries, mechanical anomalies and inter-turn short circuits in working induction motors", International Conference on Electrical Machines ICEM'98, pp. 420-25, Istanbul-Turkey, 1998.

[37] H. Henao, C. Martis, G.A. Capolino, "An equivalent internal circuit of the induction machine for advanced spectral analysis”, IEEE Industry Applications Society Conference, pp. 739-45, 2002.

[38] T. Assaf, H. Henao, G.A. Capolino, "Simplified axial flux spectrum method to detect incipient stator inter-turn shortcircuits in induction machine”, IEEE International Symposium on Industrial Electronics, pp. 815-19, Ajaccio-France, 2004. 
[39] M. Negrea, P. Jover, "Magnetic flux and supply current analysis for fault identification in electrical machines", International Aegean Conference on Electrical Machines and Power Electronics ACEMP'04, pp. 14-19, IstanbulTurkey, 2004.

[40] G.M. Joksimovic, J. Penman, "The detection of inter-turn short circuits in the stator windings of operating motors", IEEE Transactions on Industrial Electronics, Vol. 47, No. 5, pp. 1078-84, 2000.

[41] G. Gentile, N. Rotondale, M. Martelli, C. Tassoni, "Harmonic analysis of induction motors with stator faults”, Electric Machines and Power Systems, Vol. 22, No. 2, pp. 215-232, 1994.

[42] F. Filippetti, G. Gentile, S. Meo, A. Ometto, N. Rotondale, "High order current spectral components utilisation to improve induction machine diagnostics", International Conference on Electrical Machines ICEM'00, Vol. 2, pp. 94145, Espoo-Finland, 2000.

[43] G. Gentile, S. Meo, A. Ometto, "Induction motor current signature analysis to diagnostics of stator short circuits", IEEE Symposium on Diagnostics for Electrical Machines, Power Electronics and Drives SDEMPED'03, pp. 47-51, Atlanta-USA, 2003.

[44] G. Houdouin, G. Barakat, B. Dakyo, "Study of inter-turn short circuits in the stator winding of induction machines including saturation effect”, EPE Power Electronics and Motion Control EPE-PEMC'04, Riga-Latvia, 2004.

[45] Q.F. Lu, E. Ritchie, Z.T. Cao, "Experimental study of MCSA to detect stator winding inter-turn short circuit faults on cage induction motors”, International Conference on Electrical Machines ICEM'04, Cracow-Poland, 2004.

[46] S. Nandi, H.A. Toliyat, "Novel frequency-domain-based technique to detect stator interturn faults in induction machines using stator-induced voltages after switch-off”, IEEE Transactions on Industry Applications, Vol. 38, No. 1, pp. 101-09, 2002.

[47] A. Stavrou, H.G. Sedding, J. Penman, "Current monitoring for detecting inter-turn short circuits in induction motors", IEEE Transactions on Energy Conversion, Vol. 16, No. 1, pp. 32-37, 2001.

[48] W.T. Thomson, "On-line MCSA to diagnose shorted turns in low voltage stator windings of 3-phase induction motors prior to failure”, IEEE International Electric Machines and Drives Conference IEMDC'01, pp. 891-98, Boston-USA, 2001.

[49] W.T. Thomson, D. Morrison, "On-line diagnosis of stator shorted turns in mains and inverter fed low voltage induction motors”, IEE Int. Conf. on Power Electronics, Machines and Drives, pp. 122-27, Bath-UK, 2002.

[50] M. Fenger, M. Susnik, W.T. Thomson, "Development of a fully portable current signature analysis meter to detect electrical and mechanical faults in induction motor drives”, Iris Rotating Machines Conference IRMC'01, Washington D.C.-USA, 2001.

[51] M.G. Melero, M.F. Cabanas, F.R. Faya, C.H. Rojas, J. Solares, "Electromagnetic torque harmonics for on-line interturn short circuits detection in squirrel cage induction motors”, European Conference on Power Electronics and Applications EPE'99, Lausanne-Switzerland, 1999.

[52] N. Arthur, J. Penman, “Induction machine condition monitoring with higher order spectra”, IEEE Transactions on Industrial Electronics, Vol. 47, No. 5, pp. 1031-41, 2000.

[53] F.C. Trutt, J. Sottile, J.L. Kohler, “Condition monitoring of induction motor stator windings using electrically excited vibrations”, IEEE Industry Applications Conference, Vol. 4, pp. 2301-05, 2002. 